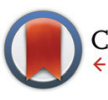

CrossMark \&lick for updates

Cite this: Org. Chem. Front., 2016, 3, 368

Received 9th December 2015 Accepted 13th January 2016

DOI: $10.1039 / c 5 q 000416 k$

rsc.li/frontiers-organic

\section{A concise total synthesis of sespenine, a structurally unusual indole terpenoid from Streptomyces $\uparrow$}

\author{
Yu Sun, ${ }^{a}$ Zhanchao Meng, ${ }^{\text {a }}$ Pengxi Chen, ${ }^{a}$ Deliang Zhang, ${ }^{a}$ Martin Baunach, ${ }^{\mathrm{b}}$ \\ Christian Hertweck ${ }^{b}$ and Ang Li*a
}

Sespenine is a structurally unusual indole sesquiterpenoid isolated from endophytic Streptomyces sp. HKI0595. Herein, we report a ten-step (the longest linear sequence) synthesis of this molecule from commercially available materials, on the basis of our first generation synthesis. Sharpless asymmetric epoxidation and Stille-Miyata coupling were used to construct a functionalized epoxy ester, which underwent Ti(II) mediated reductive radical cyclization to give a trans-decalin intermediate with a 2-methoxycarbonylindole side chain. Oxidation of this compound afforded a pair of epimeric 3-hydroxyindolenines, and the major isomer entered a bioinspired cascade of Prins cyclization/Friedel-Crafts/retro Friedel-Crafts under acidic conditions, to furnish the polycyclic core of sespenine. Sespenine analogues bearing different C2 substituents were prepared with similar chemistry. Xiamycin A, a carbazole congener of sespenine, was synthesized from the minor hydroxyindolenine epimer as well.

${ }^{a}$ State Key Laboratory of Bioorganic and Natural Products Chemistry, Collaborative Innovation Center of Chemistry for Life Sciences, Shanghai Institute of Organic Chemistry, Chinese Academy of Sciences, 345 Lingling Road, Shanghai 200032, China.E-mail:ali@sioc.ac.cn

${ }^{b}$ Leibniz Institute for Natural Product Research and Infection Biology, HKI, Jena, Germany

$\dagger$ Electronic supplementary information (ESI) available: ${ }^{1} \mathrm{H}$ and ${ }^{13} \mathrm{C}$ NMR spectra of all new compounds. See DOI: 10.1039/c5qo00416k

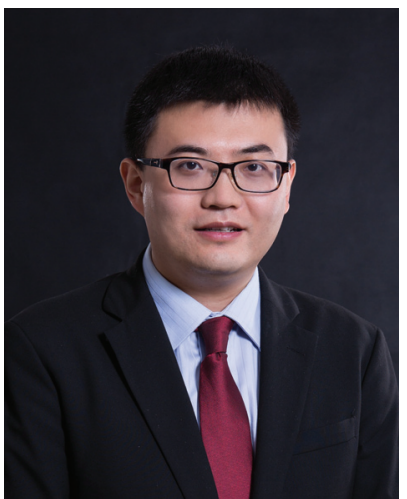

Ang Li
Ang Li was born in Jilin, China, in 1982. In 2004, he received his B.Sc. degree at Peking University, where he worked with Prof. Zhen Yang. He earned his PhD under the supervision of Prof. $K . \quad C$. Nicolaou at The Scripps Research Institute in 2009. After a brief stay as a research fellow at the Institute of Chemical and Engineering Sciences in Singapore, he joined Shanghai Institute of Organic Chemistry, Chinese Academy of Sciences, as a professor in 2010. His current research is focused on the total synthesis of structurally and biologically interesting natural products.

\section{Introduction}

Indole terpenoids have been of increasing interest in the area of chemical synthesis ${ }^{1-3}$ and biosynthesis ${ }^{4}$ because of their fascinating structures and promising biological activities. Recently, we have accomplished total syntheses of a series of indole terpenoids such as those from the anominine, drimentine, mycoleptodiscin, and hapalindole families, ${ }^{5}$ during which some useful methods and strategies have been developed. $^{6}$ In 2011, Ding et al. discovered sespenine (1, Fig. 1), a structurally unusual polycyclic molecule from Streptomyces sp. HKI0595, ${ }^{7}$ a bacterial endophyte of the

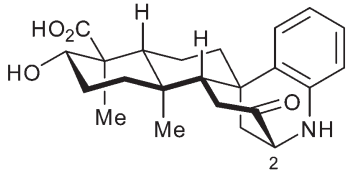

1: sespenine

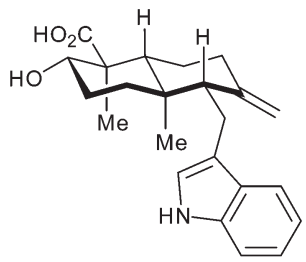

3: indosespene
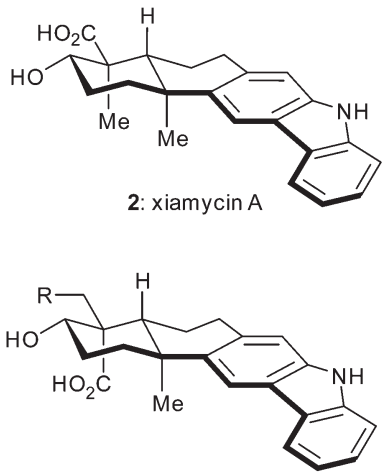

4: $\mathrm{R}=\mathrm{H}$, oridamycin $\mathrm{A}$ 5: $\mathrm{R}=\mathrm{OH}$, oridamycin $\mathrm{B}$
Fig. 1 The structures of sespenine and related indole sesquiterpenoids. 
mangrove Kandelia candel, together with a number of biogenetically relevant indole sesquiterpenoids such as xiamycin A (2) and indosespene (3). Soon after, Zhang and coworkers independently isolated several xiamycin A related natural products. ${ }^{8}$ This indole terpenoid family quickly drew attention from the perspectives of biosynthesis and chemical synthesis. ${ }^{9}$ In 2014, we accomplished the first total synthesis of sespenine (1) ${ }^{10}$ which featured a Lewis acid promoted conjugate addition and a bioinspired cationic cascade reaction. The Baran group disclosed elegant syntheses of xiamycin A (2) and dixiamycin $\mathrm{B}$; the latter possessing an $\mathrm{N}-\mathrm{N}$ linkage was assembled through an electrochemical oxidative dimerization of the former. ${ }^{11}$ We then reported syntheses of xiamycin A, indosespene, oridamycins A and B (2-5, Fig. 1), and dixiamycin $\mathrm{C}^{12}$ using two parallel strategies of $6 \pi$ electrocyclization/ aromatization $^{13-15}$ and indole $\mathrm{C} 2 \mathrm{C}-\mathrm{H}$ bond activation/Heck annulation. ${ }^{16}$ Herein, we report the second generation syntheses of sespenine (1) and xiamycin A (2) as well as the preparation of sespenine analogues with various substituents at $\mathrm{C} 2$.

\section{Results and discussion}

The retrosynthetic analysis of sespenine (1) is illustrated in Scheme 1 . The molecule is traced back to an advanced intermediate 6, which may undergo a cascade sequence of Prins cyclization/Friedel-Crafts/retro Friedel-Crafts to reach 1, via the intermediacy of the dearomatized compound 7. It is well precedented that an electron rich arene serves as a suitable
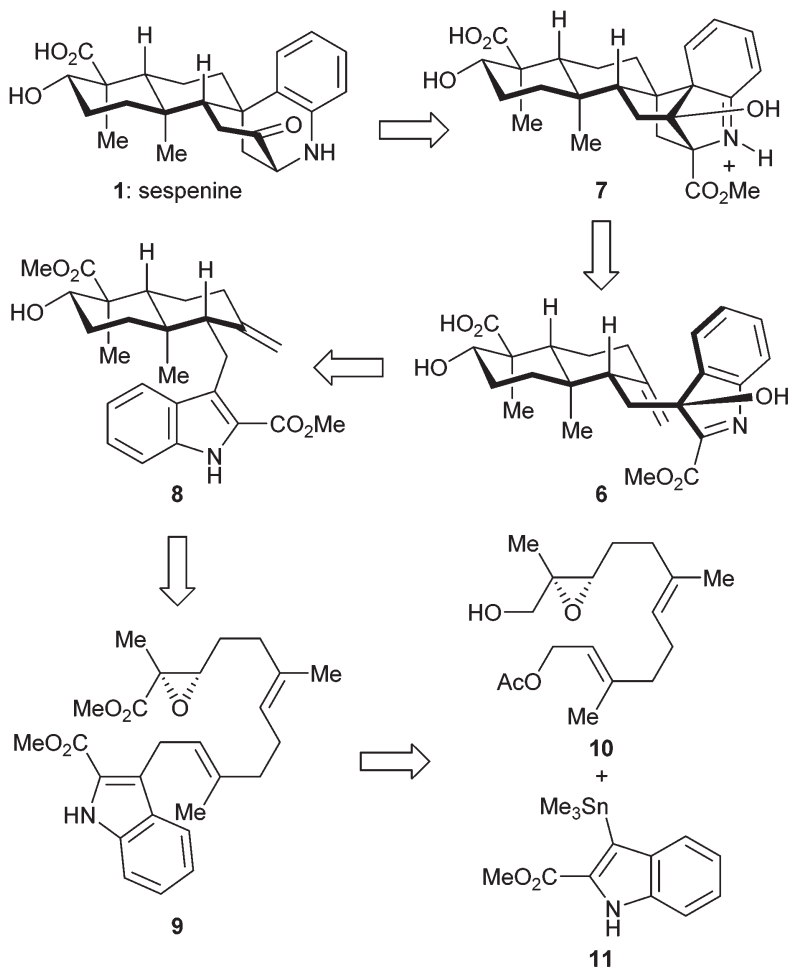

Scheme 1 Retrosynthetic analysis of sespenine. nucleophile to trap the carbocation generated through a Prins reaction. ${ }^{17,18}$ The retro Friedel-Crafts reaction from 7 to $\mathbf{1}$, which can also be viewed as a retro aldol reaction, would take advantage of the driving force of re-aromatization. Notably, Ding et al. hypothesized a similar reaction cascade in the biosynthetic pathway toward $1,{ }^{7}$ and another relevant process was proposed for the biogenesis of aspernomine, a structurally more complex indole diterpenoid, by McWhorter and Tantillo, respectively. ${ }^{19}$ A subtle change in our plan of chemical synthesis of 1, compared with the above mentioned biosynthetic speculations, is the existence of a C2 substituent (a methoxycarbonyl group in the case), which helps stabilizing the 3-hydroxyindolenine intermediate. ${ }^{20,21}$ Compound 6 is expected to arise from the precursor 8 via chemoselective oxidation of its indole moiety in the presence of an exocyclic $\mathrm{C}=\mathrm{C}$ bond. trans-Decalin $\mathbf{8}$ is simplified to $\alpha, \beta$-epoxy ester $\mathbf{9}$. Ti(III) induced epoxide opening radical reaction, which was pioneered by RajanBabu and Gansäuer, ${ }^{22}$ has been elegantly exploited by the groups of Barrero, Oltra, Fernández-Mateos, Cuerva, Roy, Reisman, etc. in complex molecule synthesis. ${ }^{23}$ Borrowing from a precedent ${ }^{12}$ in our synthesis of indosespene (3), we may rely on a reductive opening of the epoxide followed by radical cascade cyclization catalyzed by Ti(III) species in situ generated by $\mathrm{Cp}_{2} \mathrm{TiCl}_{2}$ and $\mathrm{Mn}$, to prepare 8 from 9. The indole motif should be tolerated under such conditions. Compound 9 would be disassembled into readily available building blocks allyl acetate $\mathbf{1 0}$ and stannane $\mathbf{1 1}$, the recombination of which could be effected through allyl Stille-Miyata coupling. ${ }^{24}$

The synthesis of sespenine (1) commenced with the construction of a functionalized epoxy ester 9, as shown in Scheme 2. We first explored the feasibility of Friedel-Crafts type allylation at the C3 position of commercially available methyl indole-2-carboxylate (12). However, these reactions proved to be inefficient under a variety of acidic or basic conditions, ${ }^{25}$ presumably due to the electron-deficiency of $\mathbf{1 2}$. Stannane $\mathbf{1 1}$ was then prepared from $\mathbf{1 2}$ via a two step sequence reported by Routier et $a .^{26}$ Iodination under basic conditions afforded the corresponding C3 iodide, which was converted to $\mathbf{1 1}$ through a Pd-catalyzed stannylation $\left[\mathrm{Pd}\left(\mathrm{PPh}_{3}\right)_{4}, \mathrm{Me}_{3} \mathrm{SnSnMe}_{3}\right]$. We then synthesized allyl acetate 14, which later served as a coupling partner of 11. Farnesyl acetate (13) was subjected to a two step process of allylic oxidation $\left(\mathrm{SeO}_{2}, t\right.$-BuOOH$)$ and Sharpless asymmetric epoxidation $\left[\mathrm{Ti}(\mathrm{i}-\mathrm{PrO})_{4},(+)\right.$-diethyl L-tartrate, t-BuOOH] to reach the epoxy alcohol 10, according to the known literature. ${ }^{27}$ Although this compound could be oxidized stepwise to give the corresponding carboxylic acid with good overall efficiency, treatment with a catalytic amount of 2-azaadamantane $N$-oxyl (AZADO, Scheme 2) developed by Iwabuchi $^{28}$ and stoichiometric $\mathrm{PhI}(\mathrm{OAc})_{2}$ effected the transformation in one pot. ${ }^{29}$ The resultant carboxylic acid was methylated by using $\mathrm{MeI}$ and $\mathrm{K}_{2} \mathrm{CO}_{3}$ to afford the ester $\mathbf{1 4}$ in $\mathbf{7 7 \%}$ yield for the two steps. A variety of conditions for the allyl Stille-Miyata coupling between 14 and 11 were examined. The conditions $\left[\mathrm{Pd}_{2}(\mathrm{dba})_{3}, \mathrm{i}-\mathrm{Pr}_{2} \mathrm{NEt}\right.$, $\mathrm{LiCl}$ ] modified from those described by Hegedus and coworkers proved to be optimal for delivering the coupling 

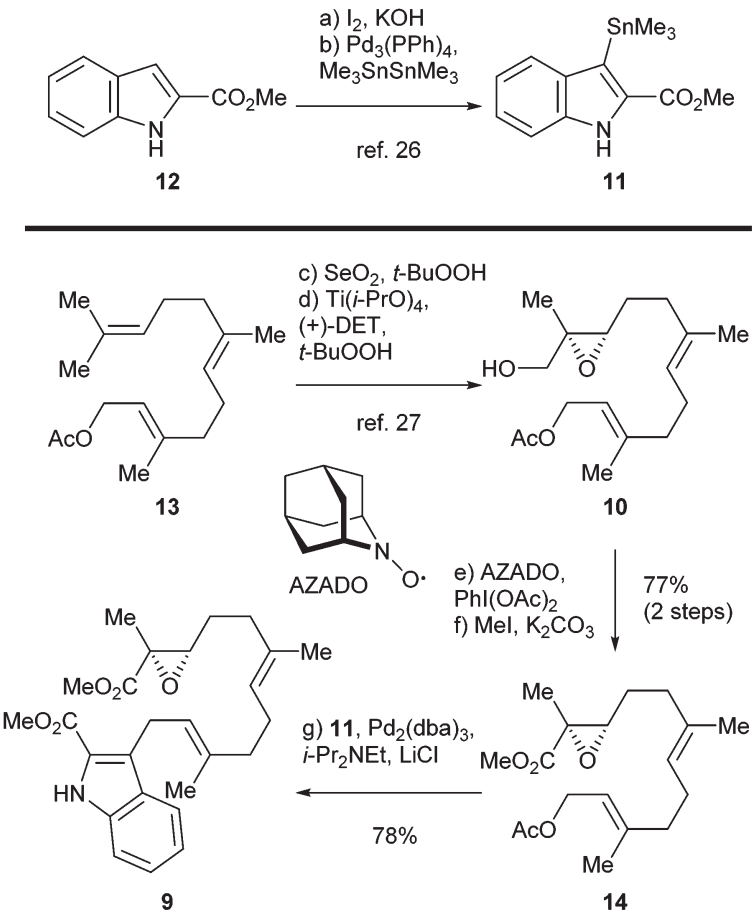

Scheme 2 Synthesis of functionalized $\alpha, \beta$-epoxy ester 9. Reagents and conditions: (e) AZADO (4 mol\%), $\mathrm{Phl}(\mathrm{OAc})_{2}$ (3.0 equiv.), $\mathrm{CH}_{2} \mathrm{Cl}_{2}, 22{ }^{\circ} \mathrm{C}$, $12 \mathrm{~h}$; (f) $\mathrm{Mel}$ (2.0 equiv.), $\mathrm{K}_{2} \mathrm{CO}_{3}$ (1.5 equiv.), DMF, $22{ }^{\circ} \mathrm{C}, 30 \mathrm{~min}, 77 \%$ (2 steps); (g) 11 (1.2 equiv.), $\mathrm{Pd}_{2}(\mathrm{dba})_{3}$ (5 mol\%), LiCl (3.0 equiv.), i- $\operatorname{Pr}_{2} \mathrm{NEt}$ (3.0 equiv.), DMF, $50{ }^{\circ} \mathrm{C}, 1 \mathrm{~h}, 78 \%$.

product 9 (78\% yield). ${ }^{24}$ Notably, the quality of stannane $\mathbf{1 1}$ was crucial to this reaction; the freshly prepared stannane was required to ensure a good coupling efficiency.

We then directed our attention to the $\mathrm{Ti}(\mathrm{III})$ mediated radical cascade cyclization for synthesizing 8 from $\mathbf{9}$. The conditions $\left[\mathrm{Cp}_{2} \mathrm{TiCl}_{2}, \mathrm{Mn}, \mathrm{TMSCl}\right.$, collidine] developed by Cuerva and coworkers were employed for the initial investigation. ${ }^{23 c}$ The anticipated product 8 with an exocyclic $\mathrm{C}=\mathrm{C}$ bond was obtained with an excellent level of stereochemical control, albeit in less than $20 \%$ yield. Over-reduction and deoxygenation, which are illustrated as reaction paths $\mathrm{a}$ and $\mathrm{b}$ in Scheme 3, respectively, turned out to be severe side reactions accompanied by the desired one. From a mechanistic perspective, the activated C16-O bond of $\alpha, \beta$-epoxy ester 9 was cleaved by $\mathrm{Ti}(\mathrm{III})$ species generated in situ by $\mathrm{Cp}_{2} \mathrm{TiCl}_{2}$ and $\mathrm{Mn}$, to initiate an electron deficient radical 15, which then underwent cascade cyclization. However, this radical could also be trapped by an excess of $\mathrm{Ti}$ (III) species to form a Ti(IV) enolate $16 ;{ }^{30}$ similar transformations are well-precedented in the context of $\mathrm{SmI}_{2}$ chemistry. ${ }^{31}$ Further $\beta$ elimination of OTi(Iv) gave an $\alpha, \beta$-unsaturated ester $\mathbf{1 7}$ as a byproduct. High concentration of $\mathrm{Ti}(\mathrm{III})$ in the reaction system increased the formation of $\mathbf{1 7}$. On the other hand, a tertiary radical $\mathbf{1 8}$ generated from the tandem cyclization may enter a Ti(III) mediated mix disproportionation pathway to reach the desired product $19,{ }^{30 a}$ or unfortunately terminate via a hydrogen atom transfer to form
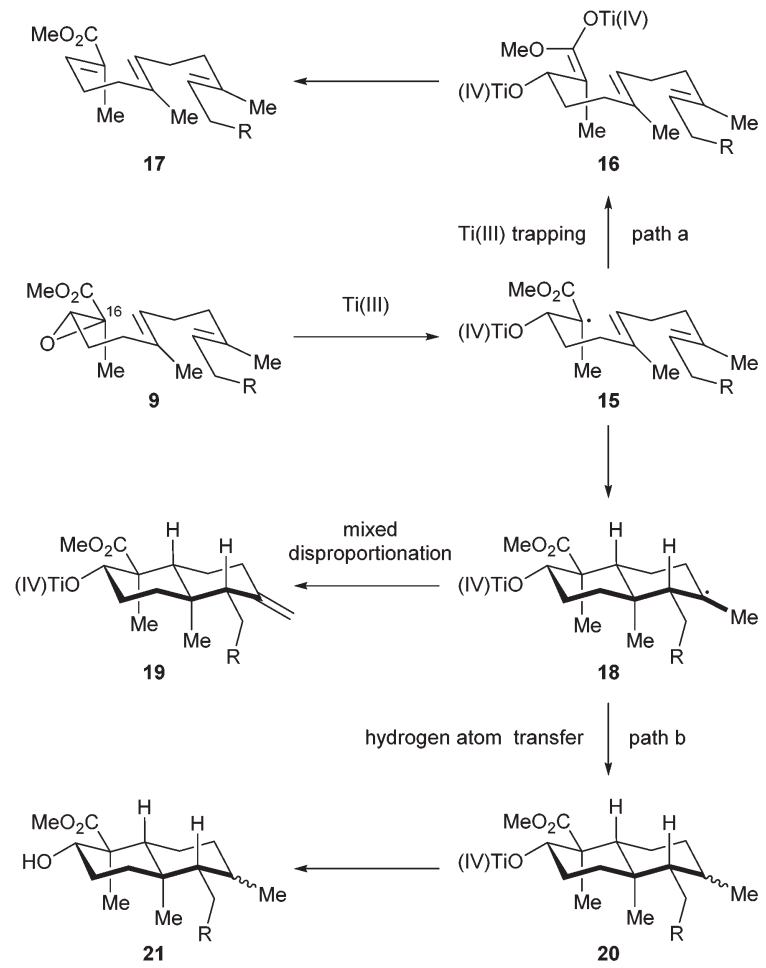

Scheme 3 Postulated pathways of the $\mathrm{Ti}(\mathrm{III})$ mediated radical reaction.

the byproduct $21 .^{32}$ Inspired by Cuerva's studies of the amine effect in $\mathrm{Ti}$ (III) chemistry ${ }^{33}$ we found that $\mathrm{i}-\mathrm{Pr}_{2} \mathrm{NEt}$ was superior to collidine as an additive for suppressing the over-reduction, and strictly anhydrous conditions were critical to inhibit the hydrogen atom transfer. Under our optimized conditions $\left[\mathrm{Cp}_{2} \mathrm{TiCl}_{2}(20 \mathrm{~mol} \%), \mathrm{Mn}, \mathrm{TMSCl}, \mathrm{i}-\mathrm{Pr}_{2} \mathrm{NEt}\right]$, compound 8 was isolated in $34 \%$ yield (Scheme 4). A suitable initial concentration of $\mathrm{Cp}_{2} \mathrm{TiCl}_{2}(0.08 \mathrm{M})$ was important as well. Considering the stereochemistry and functionality outcome of this reaction, such efficiency was acceptable and thus allowed us to carry on the synthesis.

With compound 8 in hand, we completed the syntheses of sespenine (1) and xiamycin A (2) through a divergent approach, as depicted in Scheme 4. Treatment of 8 with Oxone in acetone in the presence of aq. $\mathrm{NaHCO}_{3}$ buffer afforded a C3 epimeric mixture of hydroxyindolenine 6 and 22 in a ca. 2.8:1 ratio. The structure of $\mathbf{2 2}$ was indirectly verified by X-ray crystallographic analysis of its bis-acetylated derivative. ${ }^{34}$ Exposure of this chromatographically inseparable mixture to $\mathrm{AcOH}$ for $5 \mathrm{~h}$ at ambient temperature provided compounds $\mathbf{2 3}$ and $\mathbf{2 4}$, in $56 \%$ and $19 \%$ yields over the two steps, respectively. The former presumably arose from the devised cascade reaction, while the latter was possibly generated via a straightforward aza-Prins cyclization. ${ }^{5 b}$ The Krapcho decarboxylation $(\mathrm{NaCl}$, $170{ }^{\circ} \mathrm{C}$ ) of 23 delivered sespenine methyl ester 25 in $81 \%$ yield,$^{35}$ the structure of which was confirmed by X-ray crystallographic analysis. ${ }^{34}$ Under these conditions, the other methoxycarbonyl of the molecule remained untouched. Hydrolysis of 


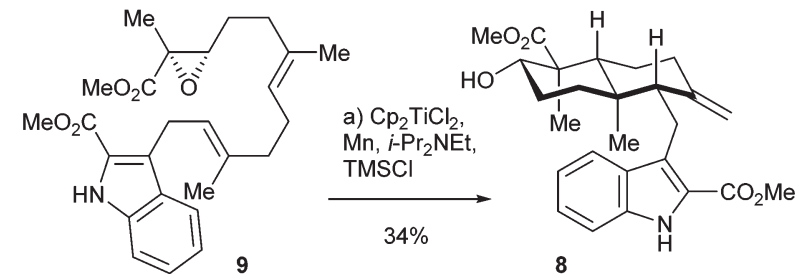

b) Oxone acetone, aq. $\mathrm{NaHCO}_{3}$

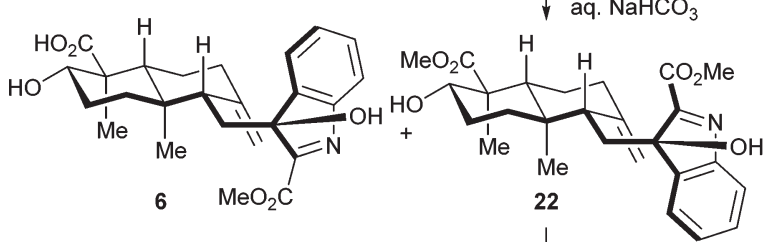
c) $\mathrm{AcOH}$
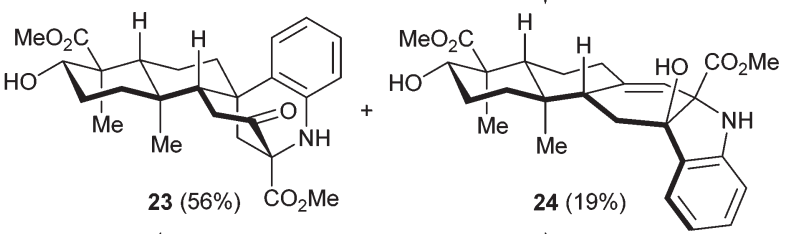

$81 \% \downarrow$ d) $\mathrm{NaCl}, 170^{\circ} \mathrm{C} \quad$ e) $\mathrm{LiCl}, 160^{\circ} \mathrm{C} \downarrow 54 \%$
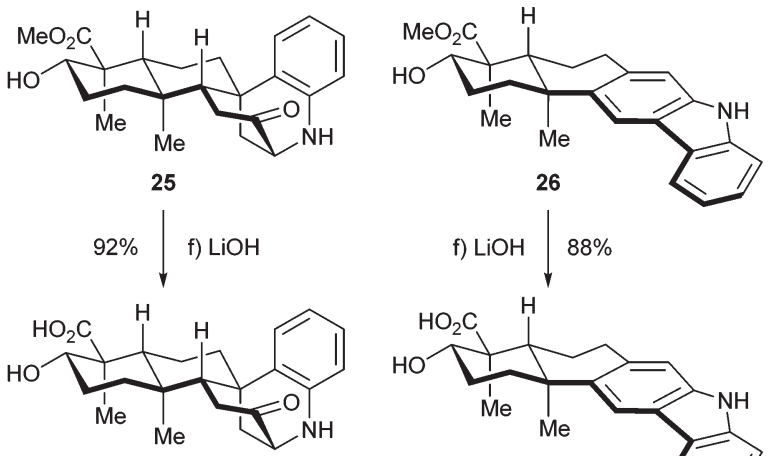

1: sespenine

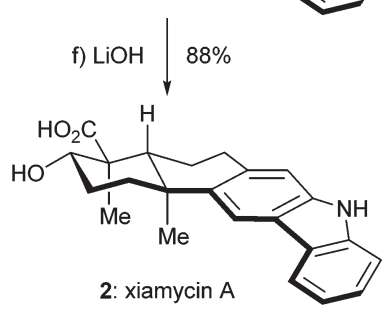

Scheme 4 Total syntheses of sespenine and xiamycin A. Reagents and conditions: (a) $\mathrm{Cp}_{2} \mathrm{TiCl}_{2}$ (20 mol\%), $\mathrm{Mn}$ (8.0 equiv.), i- $\mathrm{Pr}_{2} \mathrm{NEt}$ (6.0 equiv.), $\operatorname{TMSCl}$ (5.0 equiv.), THF, $22{ }^{\circ} \mathrm{C}, 12 \mathrm{~h}, 34 \%$; (b) Oxone (2.0 equiv.), acetone/saturated aq. $\mathrm{NaHCO}_{3}(1: 1), 22{ }^{\circ} \mathrm{C}, 15 \mathrm{~min}$; (c) $\mathrm{AcOH}(5.0$ equiv.), $\mathrm{CH}_{2} \mathrm{Cl}_{2}, 22{ }^{\circ} \mathrm{C}, 5 \mathrm{~h}, 56 \%$ for 23 (2 steps), 19\% for 24 (2 steps); (d) $\mathrm{NaCl}$ (10 equiv.), DMSO/water, $170{ }^{\circ} \mathrm{C}, 2 \mathrm{~h}, 81 \%$; (e) $\mathrm{LiCl}(10$ equiv.), DMSO/water, $160{ }^{\circ} \mathrm{C}, 1 \mathrm{~h}, 51 \%$; (f) aq. $\mathrm{LiOH}(2.0 \mathrm{M}) / \mathrm{THF} / \mathrm{MeOH}, 50{ }^{\circ} \mathrm{C}$, $10 \mathrm{~h}, 92 \%$ for $1 ; 88 \%$ for 2 .

25 with aq. LiOH rendered sespenine (1) smoothly. Interestingly, under similar Krapcho conditions ( $\mathrm{LiCl}, 160{ }^{\circ} \mathrm{C}$ ), compound 24 was directly converted into xiamycin A methyl ester 26 in 54\% yield. This one pot process may involve sequential ester hydrolysis, $\beta$-lactone formation, decarboxylation, ${ }^{36}$ and dehydrogenative aromatization. The cis orientations of the hydroxyl and carboxylic acid functionalities set the geometric basis of $\beta$-lactone formation. Basic hydrolysis furnished xiamycin A (2) with good efficiency. The spectra and physical properties of the synthetic sespenine and xiamycin A were consistent with those reported for the naturally occurring samples.

We then investigated the cationic cascade with indole substrates bearing various C2 substituents, as shown in Table 1. Sterically bulky (reverse prenyl) and electron deficient (trifluoromethyl) groups did not interfere with the tandem reaction, which indicates the wide range of stabilizing groups for 3-hydroxyindolenine intermediates. The overall yield of the two step sequence was mainly determined by the efficiency as well as the facial selectivity of the hydroxylation step, and the following cascade reaction was relatively efficient in general. Thus, a number of sespenine analogues (27-30) were readily obtained, setting the stage for further biological studies. Notably, the precursors of these compounds were synthesized through a modified version of our first generation approach (construction of an $\alpha, \beta$-unsaturated enone, conjugate addition of indole derivatives, and methylenation; see the $\mathrm{ESI} \dagger$ for details), instead of the second generation approach (StilleMiyata coupling and Ti(III)-mediated cyclization) described in this paper. To assemble one specific indosespene (3) type structure, the latter route was more efficient because of the shorter linear sequence. However, the former route was superior when a collection of such compounds needed to be synthesized for preliminary biological studies. A considerably large quantity of the enone was prepared first, and a variety of readily available indole derivatives were then added to it, to generate different analogues rapidly. In contrast, protocols for

Table 1 Preparation of sespenine analogues through the cationic cascade reaction
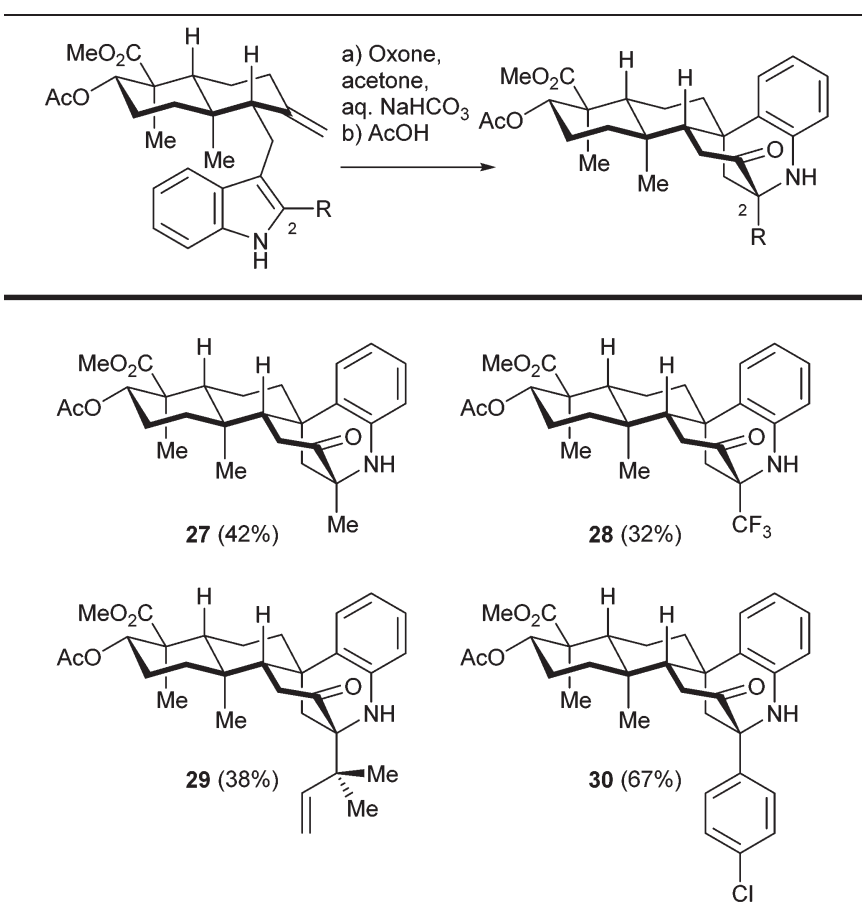

${ }^{a}$ Oxone (2.0 equiv.), acetone/saturated aq. $\mathrm{NaHCO}_{3}(1: 1), 22{ }^{\circ} \mathrm{C}$, 15 min. ${ }^{b} \mathrm{AcOH}$ (5.0 equiv.), $\mathrm{CH}_{2} \mathrm{Cl}_{2}, 22^{\circ} \mathrm{C}, 1 \mathrm{~h}$. 
preparing 2-substituted-3-stannylindoles varied according to the electronic effect and functional group compatibility, which hampered the collective synthesis via the second generation strategy.

\section{Conclusions}

We developed a ten-step (the longest linear sequence) total synthesis of sespenine from commercially available materials based on our first generation synthesis. Stille-Miyata coupling was exploited to construct a functionalized $\alpha, \beta$-epoxy ester, and Ti(III) mediated epoxide opening radical cyclization gave a trans-decalin intermediate bearing a 2-methoxycarbonylindole side chain. Indole C3 oxidation afforded a pair of epimeric 3-hydroxyindolenines, the major isomer of which then underwent a cascade of Prins cyclization/Friedel-Crafts/retro Friedel-Crafts to furnish the sespenine core. Xiamycin A was synthesized from the minor hydroxyindolenine epimer. Four analogues of sespenine with various C2 substituents were prepared. This work may facilitate the biosynthetic and biological studies of sespenine and related natural products.

\section{Acknowledgements}

This paper is dedicated to Prof. Tohru Fukuyama for his contribution to indole chemistry. We thank Prof. Changsheng Zhang and Dr Qingbo Zhang for helpful discussions. Financial support was provided by the Ministry of Science \& Technology (2013CB836900), the National Natural Science Foundation of China (21525209, 21290180, 21172235, and 21222202), Shanghai Science and Technology Commission (15JC1400400), and Chinese Academy of Sciences.

\section{Notes and references}

1 Selective examples of chemical synthesis of indole monoterpenoids: (a) H. Muratake and M. Natsume, Tetrahedron, 1990, 46, 6331; (b) H. Muratake, H. Kumagami and M. Natsume, Tetrahedron, 1990, 46, 6351; (c) V. Vaillancourt and K. F. Albizati, J. Am. Chem. Soc., 1993, 115, 3499; (d) T. Fukuyama and X. Chen, J. Am. Chem. Soc., 1994, 116, 3125; (e) M. Sakagami, H. Muratake and M. Natsume, Chem. Pharm. Bull., 1994, 42, 1393; $(f)$ A. C. Kinsman and M. A. Kerr, Org. Lett., 2001, 3, 3189; $(g)$ A. C. Kinsman and M. A. Kerr, J. Am. Chem. Soc., 2003, 125, 14120; (h) P. S. Baran and J. M. Richter, J. Am. Chem. Soc., 2004, 126, 7450; (i) P. S. Baran and J. M. Richter, J. Am. Chem. Soc., 2005, 127, 15394; (j) P. S. Baran, T. J. Maimone and J. M. Richter, Nature, 2007, 446, 404; (k) J. M. Richter, Y. Ishihara, T. Masuda, B. W. Whitefield, T. Llamas, A. Pohjakallio and P. S. Baran, J. Am. Chem. Soc., 2008, 130, 17938; (l) T. J. Maimone, Y. Ishihara and P. S. Baran, Tetrahedron, 2015, 71, 3652; (m) S. E. Reisman, J. M. Ready, A. Hasuoka, C. J. Smith and J. L. Wood, J. Am. Chem. Soc.,
2006, 128, 1448; (n) A. Chandra and J. N. Johnston, Angew. Chem., Int. Ed., 2011, 50, 7641; (o) R. J. Rafferty and R. M. Williams, J. Org. Chem., 2012, 77, 519; (p) V. Bhat, K. M. Allan and V. H. Rawal, J. Am. Chem. Soc., 2011, 133, 5798; (q) K. M. Allan, K. Kobayashi and V. H. Rawal, J. Am. Chem. Soc., 2012, 134, 1392; (r) A. D. Huters, K. W. Quasdorf, E. D. Styduhar and N. K. Garg, J. Am. Chem. Soc., 2011, 133, 15797; (s) K. W. Quasdorf, A. D. Huters, M. W. Lodewyk, D. J. Tantillo and N. K. Garg, J. Am. Chem. Soc., 2012, 134, 1396; $(t)$ A. D. Huters, E. D. Styduhar and N. K. Garg, Angew. Chem., Int. Ed., 2012, 51, 3758; (u) E. D. Styduhar, A. D. Huters, N. A. Weires and N. K. Garg, Angew. Chem., Int. Ed., 2013, 52, 12422; (v) N. A. Weires, E. D. Styduhar, E. L. Baker and N. K. Garg, J. Am. Chem. Soc., 2014, 136, 14710.

2 Selective examples of chemical synthesis of indole sesquiterpenoids: (a) E. J. Velthuisen and S. J. Danishefsky, J. Am. Chem. Soc., 2007, 129, 10640; (b) I. S. Marcos, R. F. Moro, I. P. Costales, P. Basabe, D. Díez, F. Mollinedo and J. G. Urones, Tetrahedron, 2012, 68, 7932; (c) I. S. Marcos, R. F. Moro, I. Costales, P. Basabe and D. Díez, Nat. Prod. Rep., 2013, 30, 1509; (d) I. S. Marcos, R. F. Moro, I. Costales, P. Basabe, D. Díez, F. Mollinedo and J. G. Urones, Tetrahedron, 2013, 69, 7285; (e) A. Asanuma, M. Enomoto, T. Nagasawa and S. Kuwahara, Tetrahedron Lett., 2013, 54, 4561.

3 Selective examples of chemical synthesis of indole diterpenoids: (a) A. B. Smith III and R. Mewshaw, J. Am. Chem. Soc., 1985, 107, 1769; (b) A. B. Smith III, T. Sunazuka, T. L. Leenay and J. Kingery-Wood, J. Am. Chem. Soc., 1990, 112, 8197; (c) A. B. Smith III, N. Kanoh, H. Ishiyama and R. A. Hartz, J. Am. Chem. Soc., 2000, 122, 11254; (d) Y. Zou, J. E. Melvin, S. S. Gonzales, M. J. Spafford and A. B. Smith III, J. Am. Chem. Soc., 2015, 137, 7095; (e) B. Bradshaw, G. Etxebarria-Jardí and J. Bonjoch, J. Am. Chem. Soc., 2010, 132, 5966; $(f)$ A. E. Goetz, A. L. Silberstein, M. A. Corsello and N. K. Garg, J. Am. Chem. Soc., 2014, 136, 3036; (g) M. Enomoto, A. Morita and S. Kuwahara, Angew. Chem., Int. Ed., 2012, 51, 12833; (h) R. J. Sharpe and J. S. Johnson, J. Am. Chem. Soc., 2015, 137, 4968; (i) R. J. Sharpe and J. S. Johnson, J. Org. Chem., 2015, 80, 9740.

4 Selected studies of biosynthesis of indole terpenoids: (a) S. E. O'Connor and E. McCoy, Terpene Indole Alkaloid Biosynthesis, in Recent Advances in Phytochemistry, ed. J. T. Romeo, Elsevier, Amsterdam, 2006, vol. 40, pp. 1-22; (b) M. Baunach, J. Franke and C. Hertweck, Angew. Chem., Int. Ed., 2015, 54, 2604; (c) K. Tagami, C. Liu, A. Minami, M. Noike, T. Isaka, S. Fueki, Y. Shichijo, H. Toshima, K. Gomi, T. Dairi and H. Oikawa, J. Am. Chem. Soc., 2013, 135, 1260; (d) M. Tang, H. Lin, D. Li, Y. Zou, J. Li, W. Xu, R. Cacho, M. E. Hillenmeyer, N. K. Garg and Y. Tang, J. Am. Chem. Soc., 2015, 137, 13724.

5 Total syntheses of indole terpenoids from our group: (a) M. Bian, Z. Wang, X. Xiong, Y. Sun, C. Matera, K. C. Nicolaou and A. Li, J. Am. Chem. Soc., 2012, 134, 8078; (b) Y. Sun, R. Li, W. Zhang and A. Li, Angew. Chem., Int. Ed., 
2013, 52, 9201; (c) Z. Lu, M. Yang, P. Chen, X. Xiong and A. Li, Angew. Chem., Int. Ed., 2014, 53, 13840; (d) S. Zhou, H. Chen, Y. Luo, W. Zhang and A. Li, Angew. Chem., Int. Ed., 2015, 54, 6878; (e) Z. Lu, H. Li, M. Bian and A. Li, J. Am. Chem. Soc., 2015, 137, 13764.

6 (a) S. Zhou, D. Zhang, Y. Sun, R. Li, W. Zhang and A. Li, Adv. Synth. Catal., 2014, 356, 2867; (b) X. Xiong, D. Zhang, J. Li, Y. Sun, S. Zhou, M. Yang, H. Shao and A. Li, Chem. Asian J., 2015, 10, 869; (c) H. Yu, C. Wan, J. Han and A. Li, Acta Chim. Sin., 2013, 71, 1488.

7 (a) L. Ding, A. Maier, H.-H. Fiebig, W.-H. Lin and C. Hertweck, Org. Biomol. Chem., 2011, 9, 4029; discovery of relevant natural products: (b) L. Ding, J. Münch, H. Goerls, A. Maier, H.-H. Fiebig, W.-H. Lin and C. Hertweck, Bioorg. Med. Chem. Lett., 2010, 20, 6685.

8 Q. Zhang, A. Mándi, S. Li, Y. Chen, W. Zhang, X. Tian, H. Zhang, H. Li, W. Zhang, S. Zhang, J. Ju, T. Kurtán and C. Zhang, Eur. J. Org. Chem., 2012, 5256.

9 (a) Z. Xu, M. Baunach, L. Ding and C. Hertweck, Angew. Chem., Int. Ed., 2012, 51, 10293; (b) M. Baunach, L. Ding, T. Bruhn, G. Bringmann and C. Hertweck, Angew. Chem., Int. Ed., 2013, 52, 9040; (c) M. Baunach, L. Ding, K. Willing and C. Hertweck, Angew. Chem., Int. Ed., 2015, 54, 13279; (d) H. Li, Q. Zhang, S. Li, Y. Zhu, G. Zhang, H. Zhang, X. Tian, S. Zhang, J. Ju and C. Zhang, J. Am. Chem. Soc., 2012, 134, 8996; (e) Q. Zhang, H. Li, S. Li, Y. Zhu, G. Zhang, H. Zhang, W. Zhang, R. Shi and C. Zhang, Org. Lett., 2012, 14, 6142; $(f)$ H. Li, Y. Sun, Q. Zhang, Y. Zhu, S.-M. Li, A. Li and C. Zhang, Org. Lett., 2015, 17, 306; ( $g$ ) A. H. Trotta, Org. Lett., 2015, 17, 3358.

10 Y. Sun, P. Chen, D. Zhang, M. Baunach, C. Hertweck and A. Li, Angew. Chem., Int. Ed., 2014, 53, 9012.

11 B. R. Rosen, E. W. Werner, A. G. O'Brien and P. S. Baran, J. Am. Chem. Soc., 2014, 136, 5571.

12 Z. Meng, H. Yu, L. Li, W. Tao, H. Chen, M. Wan, P. Yang, D. J. Edmonds, J. Zhong and A. Li, Nat. Commun., 2015, 6, 6096.

13 Selected examples of $6 \pi$-electrocyclization/aromatization in natural product synthesis: (a) E. A. Anderson, E. J. Alexanian and E. J. Sorensen, Angew. Chem., Int. Ed., 2004, 43, 1998; (b) K. Ohmori, K. Mori, Y. Ishikawa, H. Tsuruta, S. Kuwahara, N. Harada and K. Suzuki, Angew. Chem., Int. Ed., 2004, 43, 3167; (c) T. Suzuki, T. Hamura and K. Suzuki, Angew. Chem., Int. Ed., 2008, 47, 2248; (d) D. L. Sloman, B. Mitasev, S. S. Scully, J. A. Beutler and J. A. Porco, Angew. Chem., Int. Ed., 2011, 50, 2511; (e) D. L. Sloman, J. W. Bacon and J. A. Porco, J. Am. Chem. Soc., 2011, 133, 9952; $(f)$ D. K. Winter, M. A. Endoma-Arias, T. Hudlicky, J. A. Beutler and J. A. Porco, J. Org. Chem., 2013, 78, 7617; $(g)$ A. Fürstner, M. M. Domostoj and B. Scheiper, J. Am. Chem. Soc., 2005, 127, 11620; (h) T. J. Greshock and R. L. Funk, J. Am. Chem. Soc., 2006, 128, 4946; (i) T. J. Greshock and R. L. Funk, Org. Lett., 2006, 8, 2643; (j) R. J. Huntley and R. L. Funk, Org. Lett., 2006, 8, 3403; (k) R. J. Huntley and R. L. Funk, Org. Lett., 2006, 8, 4775; (l) S. T. Staben, J. J. Kennedy-Smith, D. Huang,
B. K. Corkey, R. L. LaLonde and F. D. Toste, Angew. Chem., Int. Ed., 2006, 45, 5991.

14 Other examples of $6 \pi$-electrocyclization/aromatization in natural product synthesis from our group: (a) Z. Lu, Y. Li, J. Deng and A. Li, Nat. Chem., 2013, 5, 679; (b) J. Li, P. Yang, M. Yao, J. Deng and A. Li, J. Am. Chem. Soc., 2014, 136, 16477; (c) M. Yang, J. Li and A. Li, Nat. Commun., 2015, 6, 6445; (d) M. Wan, M. Yao, J.-Y. Gong, P. Yang, H. Liu and A. Li, Chin. Chem. Lett., 2015, 26, 272; (e) M. Yang, X. Yang, H. Sun and A. Li, Angew. Chem., Int. Ed., DOI: 10.1002/anie.201510568.

15 An excellent review of biosynthetic and biomimetic electrocyclizations: C. M. Beaudry, J. P. Malerich and D. Trauner, Chem. Rev., 2005, 105, 4757.

16 (a) P. S. Baran and E. J. Corey, J. Am. Chem. Soc., 2002, 124, 7904; (b) E. M. Ferreira and B. M. Stoltz, J. Am. Chem. Soc., 2003, 125, 9578; (c) N. P. Grimster, C. Gauntlett, C. R. A. Godfrey and M. J. Gaunt, Angew. Chem., Int. Ed., 2005, 44, 3125; (d) A. Kong, X. Han and X. Lu, Org. Lett., 2006, 8, 1339; (e) X. Han and X. Lu, Org. Lett., 2009, 11, 2381.

17 (a) C. Olier, M. Kaafarani, S. Gastaldi and M. P. Bertrand, Tetrahedron, 2010, 66, 413; (b) X. Han, G. R. Peh and P. E. Floreancig, Eur. J. Org. Chem., 2013, 1193.

18 Application of Prins cyclization in natural product synthesis from our group: J. Deng, S. Zhou, W. Zhang, J. Li, R. Li and A. Li, J. Am. Chem. Soc., 2014, 136, 8185. Also see ref. $5 b, c$ and $e$.

19 (a) Y. Liu, W. W. McWhorter Jr. and C. E. Hadden, Org. Lett., 2003, 5, 333; (b) G. A. Ho, D. H. Nouri and D. J. Tantillo, Tetrahedron Lett., 2009, 50, 1578.

20 2-substituted 3-hydroxyindolenines as natural product motifs: (a) M. Bittner, M. Silva, E. M. Gopalakrishna, W. H. Watson, V. Zabel, S. A. Matlin and P. G. Sammes, J. Chem. Soc., Chem. Commun., 1978, 79; (b) I. R. C. Bick, M. A. Hai and N. W. Preston, Heterocycles, 1983, 20, 667; (c) D. Ponglux, S. Wongseripipatana, H. Takayama, M. Kikuchi, M. Kurihara, M. Kitajima, N. Aimi and S. Sakai, Planta Med., 1994, 60, 580.

21 Selected examples of syntheses of 2-substituted 3-hydroxyindolenines: (a) B. Witkop and J. B. Patrick, J. Am. Chem. Soc., 1951, 73, 2188; (b) T. Hino, H. Yamaguchi, K. Matsuki, K. Nakano, M. Sodeoka and M. Nakagawa, J. Chem. Soc., Perkin Trans. 1, 1983, 141; (c) R. Güller and H.-J. Borschberg, Helv. Chim. Acta, 1993, 76, 1847; (d) J. Éles, G. Kalaus, A. Lévai, I. Greiner, M. Kajtár-Peredy, P. Szabó, L. Szabó and C. Szántay, J. Heterocycl. Chem., 2002, 39, 767; (e) M. Movassaghi, M. A. Schmidt and J. A. Ashenhurst, Org. Lett., 2008, 10, 4009; (f) T. J. Greshock and R. M. Williams, Org. Lett., 2007, 9, 4255; (g) T. J. Greshock and R. M. Williams, Org. Lett., 2012, 14, 6377; (h) S. Liu, J. S. Scotti and S. A. Kozmin, J. Org. Chem., 2013, 78, 8645; (i) S. Han, K. C. Morrison, P. J. Hergenrother and M. Movassaghi, J. Org. Chem., 2014, 79, 473; (j) X. Qi, H. Bao and U. K. Tambar, J. Am. Chem. Soc., 2011, 133, 10050; (k) S. Han and M. Movassaghi, 
J. Am. Chem. Soc., 2011, 133, 10768; (l) S. Liu and X.-J. Hao, Tetrahedron Lett., 2011, 52, 5640; $(m)$ F. Kolundzic, M. N. Noshi, M. Tjandra, M. Movassaghi and S. J. Miller, J. Am. Chem. Soc., 2011, 133, 9104.

22 (a) W. A. Nugent and T. V. RajanBabu, J. Am. Chem. Soc., 1988, 110, 8561; (b) T. V. RajanBabu and W. A. Nugent, J. Am. Chem. Soc., 1994, 116, 986; (c) A. Gansäuer, M. Pierobon and H. Bluhm, Angew. Chem., Int. Ed., 1998, 37, 101; (d) A. Gansäuer, H. Bluhm and M. Pierobon, J. Am. Chem. Soc., 1998, 120, 12849; (e) A. Gansäuer and S. Narayan, Adv. Synth. Catal., 2002, 344, 465; (f) A. Gansäuer, J. Justicia, C.-A. Fan, D. Worgull and F. Piestert, Top. Curr. Chem., 2007, 279, 25.

23 (a) A. Fernández-Mateos, E. Martin de la Nava, G. Pascual Coca, A. Ramos Silva and R. Rubio González, Org. Lett., 1999, 1, 607; (b) A. F. Barrero, J. M. Cuerva, M. M. Herrador and M. V. Valdivia, J. Org. Chem., 2001, 66, 4074; (c) J. Justicia, A. Rosales, E. Buñuel, J. L. Oller-López, M. Valdivia, A. Haïdour, J. E. Oltra, A. F. Barrero, D. J. Cárdenas and J. M. Cuerva, Chem. - Eur. J., 2004, 10, 1778; (d) J. Justicia, J. E. Oltra and J. M. Cuerva, J. Org. Chem., 2004, 69, 5803; (e) J. Justicia, J. L. Oller-López, A. G. Campaña, J. E. Oltra, J. M. Cuerva, E. Buñuel and D. J. Cárdenas, J. Am. Chem. Soc., 2005, 127, 14911; (f) J. Justicia, J. E. Oltra and J. M. Cuerva, J. Org. Chem., 2005, 70, 8265; (g) A. F. Barrero, J. F. Quílez del Moral, E. M. Sánchez and J. F. Arteaga, Eur. J. Org. Chem., 2006, 7, 1627; (h) J. M. Cuerva, J. Justicia, J. L. Oller-López and J. E. Oltra, Top. Curr. Chem., 2006, 264, 63; (i) J. Justicia, L. Álvarez de Cienfuegos, A. G. Campaña, D. Miguel, V. Jakoby, A. Gansäuer and J. M. Cuerva, Chem. Soc. Rev., 2011, 40, 3525; (j) S. P. Morcillo, D. Miguel, A. G. Campaña, L. Álvarez de Cienfuegos, J. Justicia and J. M. Cuerva, Org. Chem. Front., 2014, 1, 15; (k) S. P. Morcillo, D. Miguel, S. Resa, A. Martín-Lasanta, A. Millán, D. Choquesillo-Lazarte, J. M. García-Ruiz, A. J. Mota, J. Justicia and J. M. Cuerva, J. Am. Chem. Soc., 2014, 136, 6943; (l) J. Y. Cha, J. T. S. Yeoman and
S. E. Reisman, J. Am. Chem. Soc., 2011, 133, 14964; (m) J. T. S. Yeoman, V. W. Mak and S. E. Reisman, J. Am. Chem. Soc., 2013, 135, 11764; (n) P. K. Mandal, G. Maiti and S. C. Roy, J. Org. Chem., 1998, 63, 2829; (o) S. C. Roy, K. K. Rana and C. Guin, J. Org. Chem., 2002, 67, 3242.

24 L. Del Valle, J. K. Stille and L. S. Hegedus, J. Org. Chem., 1990, 55, 3019.

25 (a) Z. Liu, L. Liu, Z. Shafiq, D. Wang and Y.-J. Chen, Lett. Org. Chem., 2007, 4, 256; (b) X. Zhu and A. Ganesan, J. Org. Chem., 2002, 67, 2705; (c) M. Westermaier and H. Mayr, Org. Lett., 2006, 8, 4791.

26 A. Bourderioux, A. Ouach, V. Bénéteau, J. Mérour and S. Routier, Synthesis, 2010, 783.

27 J. Lan, Z. Liu, H. Yuan, L. Peng, W. Li, Y. Li, Y. Li and A. C. Chan, Tetrahedron Lett., 2000, 41, 2181.

28 (a) M. Shibuya, M. Tomizawa, I. Suzuki and Y. Iwabuchi, J. Am. Chem. Soc., 2006, 128, 8412; (b) Y. Iwabuchi, Chem. Pharm. Bull., 2013, 61, 1197.

29 T. Kuranaga, Y. Sesoko, K. Sakata, N. Maeda, A. Hayata and M. Inoue, J. Am. Chem. Soc., 2013, 135, 5467.

30 (a) J. Justicia, T. Jiménez, S. P. Morcillo, J. M. Cuerva and J. E. Oltra, Tetrahedron, 2009, 65, 10837; (b) C. Hardouin, F. Chevallier, B. Rousseau and E. Doris, J. Org. Chem., 2001, 66, 1046.

31 K. C. Nicolaou, S. P. Ellery and J. S. Chen, Angew. Chem., Int. Ed., 2009, 48, 7140.

32 (a) J. M. Cuerva, A. G. Campaña, J. Justicia, A. Rosales, J. L. Oller-López, R. Robles, D. J. Cárdenas, E. Buñuel and J. E. Oltra, Angew. Chem., Int. Ed., 2006, 45, 5522; (b) T. V. Chciuk and R. A. Flowers II, J. Am. Chem. Soc., 2015, 137, 11526.

33 M. Paradas, A. G. Campaña, T. Jiménez, R. Robles, J. E. Oltra, E. Buñuel, J. Justicia, D. J. Cárdenas and J. M. Cuerva, J. Am. Chem. Soc., 2010, 132, 12748.

34 CCDC 987752 (bis-acetylated 22) and 949307 (25) contain the supplementary crystallographic data for this paper.

35 A. P. Krapcho, ARKIVOC, 2007, (ii), 54.

36 A. Pommier and J.-M. Pons, Synthesis, 1993, 441. 